\title{
Postprandial symptoms in dysmotility-like functional dyspepsia are not related to disturbances of gastric myoelectrical activity
}

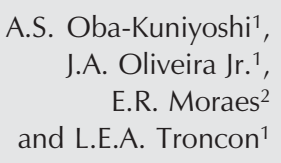

A.S. Oba-Kuniyoshi ${ }^{1}$, J.A. Oliveira Jr. ${ }^{1}$, E.R. Moraes ${ }^{2}$ and L.E.A. Troncon ${ }^{1}$

Departamentos de ${ }^{1}$ Clínica Médica, Faculdade de Medicina de Ribeirão Preto, and ${ }^{2}$ Física e Matemática, Faculdade de Filosofia, Ciências e Letras de Ribeirão Preto, Universidade de São Paulo, Ribeirão Preto, SP, Brasil

\section{Correspondence \\ L.E.A. Troncon \\ Departamento de Clínica Médica \\ Hospital das Clínicas, FMRP, USP \\ 14048-900 Ribeirão Preto, SP \\ Brasil \\ Fax: +55-16-633-6695 \\ E-mail: ledatron@fmrp.usp.br \\ The present address of E.R. Moraes \\ is Instituto de Pesquisa e \\ Desenvolvimento, Universidade do Vale do Paraíba, Av. Shishima Hifumi, 2911, 12244-000 São José do \\ Campos, SP, Brasil.}

Research supported by PRONEX/ FINEP/CNPq and FAEPA/HCFMRP.

Publication supported by FAPESP.

Received March 17, 2003

Accepted October 30, 2003

\begin{abstract}
Gastric dysrhythmias, such as tachy- or bradygastria, have been reported in patients with functional dyspepsia (FD), but their role in symptom production is uncertain. It is also not known whether gastric dysrhythmias in these patients can be elicited by physiological gastric distension with a meal. We investigated the relationships between symptoms after ingestion of different volumes of water following a test meal and gastric dysrhythmias in FD patients. Fourteen patients with dysmotility-like FD and 13 healthy volunteers underwent paired electrogastrography (EGG) studies. Fasted subjects ingested $150 \mathrm{ml}$ of yoghurt with either $150 \mathrm{ml}$ (low volume) or $300 \mathrm{ml}$ (high volume) water in random order. Fasting and fed EGGs with monitoring of symptoms were performed in both studies. Ten FD patients (71.4\%) reported upper abdominal discomfort and bloating after the low volume meal, but only one $(7.1 \%)$ presented an abnormal EGG (dominant frequency in the 2-4-cpm range: 58\%). Following the high volume meal, 7 patients (50\%) had symptoms, but none had EGG abnormalities. No significant differences were found between FD patients and controls for any of the EGG variables, in any test. In FD patients with postprandial symptoms, the percentage of the EGG dominant frequency in the normal range (median, $84.6 \%$; range, 76.0$100.0 \%)$ was similar $(\mathrm{P}>0.20)$ to that in those without symptoms (88.5\%; 75.0-100.0\%). We conclude that disturbances of gastric myoelectrical activity are unlikely to play a role in the origin of postprandial upper abdominal discomfort and bloating in dysmotilitylike FD.
\end{abstract}

\section{Introduction}

Functional dyspepsia is a common clinical condition defined by pain or discomfort centered in the upper abdomen, which is not explained by any identifiable structural or biochemical abnormality $(1,2)$. A number of studies have shown that patients with this condition may have disordered gastric motil-
Key words

- Functional dyspepsia

- Gastric myoelectrical activity

- Electrogastrography

- Postprandial symptoms ...................... 
cycles per minute (12). Abnormally high ("tachygastria") or low ("bradygastria") frequencies of gastric electrical oscillations have been detected by surface electrode recording (electrogastrography, EGG) in a variety of clinical conditions, usually in association with antral hypomotility and delayed gastric emptying (12), such as in idiopathic (13) and diabetic (14) gastroparesis. Disturbances of gastric myoelectrical activity have also been described in patients with functional dyspepsia presenting symptoms suggestive of motility disorders of the upper gastrointestinal tract (3-5,15-17). However, the origin of these disturbances and the role of gastric dysrhythmias in symptom production in functional dyspepsia are unclear.

In a previous study, we demonstrated that graded distension of the gastric fundus with a plastic bag elicited greater instability in gastric myoelectrical rhythm in patients with functional dyspepsia (18). We therefore determined whether physiological ingestion of increasing volumes of water following a standard test meal would induce disturbances of gastric myoelectrical activity in functional dyspepsia patients, which could be related to symptom production.

\section{Patients and Methods}

Fourteen patients with dysmotility-like functional dyspepsia and 13 healthy volunteers participated in the study after giving informed consent. The protocol for the study was approved by the Ethics Committee (Statement number 7244/98) of our University Hospital.

\section{Patients}

The group of patients with functional dyspepsia consisted of 9 women and 5 men with a median age of 44 years (range: 20-54 years). Body weight ranged from 48 to $85 \mathrm{~kg}$ (median: $59.5 \mathrm{~kg}$ ), and body mass index ranged from 20.19 to $34.91 \mathrm{~kg} / \mathrm{m}^{2}$ (median: $24.24 \mathrm{~kg} / \mathrm{m}^{2}$ ).
All patients complained of chronic, persistent, or recurrent non-painful discomfort in the upper abdomen after meals as the predominant symptom and fulfilled Rome II criteria for dysmotility-like functional dyspepsia (2). All patients had chronic, severe postprandial fullness in the absence of any abnormality on upper gastrointestinal endoscopy and upper abdominal ultrasonography. On the basis of the answers to a structured questionnaire whose objective was to characterize dyspeptic symptoms, it was found that all patients had upper abdominal discomfort following meals, 11 patients had early satiety, defined as the inability to complete a normal size meal, bloating was present in 10 cases, and nausea was reported by 6 of the 14 patients. As a whole, symptoms were regarded by all patients as severe enough to interfere with both their usual activities and feeding habits.

None of the patients had previous surgery of the gastrointestinal tract, except for appendectomy, or had evidence of any systemic disease, which was additionally excluded by common laboratory tests and serological reactions for Chagas' disease. None were regularly using any medication, but all were specifically instructed not to take any drug for at least $72 \mathrm{~h}$ before the studies.

\section{Control group}

The control group consisted of 13 healthy asymptomatic volunteers ( 8 women and 5 men), with a median age of 40 years (range: 22-51 years), who were selected from the medical staff and student population of the University Hospital. In this group, body weight ranged from 48 to $80 \mathrm{~kg}$ (median: $63.0 \mathrm{~kg}$ ) and body mass index ranged from 20.86 to 30.51 $\mathrm{kg} / \mathrm{m}^{2}$ (median: $24.44 \mathrm{~kg} / \mathrm{m}^{2}$ ). None had a history of any gastrointestinal or systemic disease or previous digestive operations.

\section{Study protocol}

Patients and control subjects underwent 
two EGG studies on two different days. In each study, subjects drank either $150 \mathrm{ml}$ (low volume) or $300 \mathrm{ml}$ (high volume) water in random order after the ingestion of a standard test meal consisting of $150 \mathrm{ml}$ of yoghurt (carbohydrates: $21 \mathrm{~g}$, lipids: $12 \mathrm{~g}$, protein: $12 \mathrm{~g}$, total calorie content: $240 \mathrm{kcal}$ ). All studies were performed in the morning after a fasting period of at least $6 \mathrm{~h}$. Just before and every $5 \mathrm{~min}$ after the ingestion of the test meal, upper gastrointestinal symptoms were evaluated. Women from both the dyspepsia and control groups were studied only during the first period of the menstrual cycle, so as to avoid undesirable influences on EGG results (19). The interval between the two EGG studies ranged from 1 to 30 days (median: 14 days).

\section{Electrogastrography}

EGG recordings were carried out for 30 $\min$ in the fasting state and for another 30 min after test meal ingestion. Subjects were placed in a comfortable recumbent position and were instructed to remain as quiet as possible for the entire study. The abdominal skin was cleaned with water and ordinary soap and shaved when necessary, after which gentle skin abrasion was performed using an appropriate gel (Omni-Prep, D.O. Weaver \& Co., Aurora, CO, USA). A conductive cream (Parker Laboratories, Inc., Orange, NJ, USA) was then applied to the skin and $3 \mathrm{Ag}-\mathrm{AgCl}$ electrodes (Anamed Medical Instruments, São Paulo, SP, Brazil) were affixed to the abdomen at standard positions. A first electrode connected to one of the active leads was positioned in the midline, halfway between the xiphoid process and the umbilicus. The second electrode was placed on the patient's left side, approximately $1 \mathrm{~cm}$ below the bottom rib, and $5 \mathrm{~cm}$ above the first electrode at a $45^{\circ}$ angle. A third electrode, which was connected to the reference lead, was positioned below the right bottom rib, so as to form an equilateral triangle with the other electrodes.

EGG recordings were performed with a commercially available recorder (PC Polygraph, Synetics Medical AB, Stockholm, Sweden) containing pre-amplifiers and filters for recording of electrical oscillations with frequencies ranging from 0.0 to 18 cycles per min (cpm). The EGG signal was captured and digitized using a sampling frequency of $4 \mathrm{~Hz}$ and stored on the hard disk of a personal computer. All recordings were inspected for gross motion artifacts, which were removed digitally before data analysis.

\section{Data analysis}

Data were processed using specific software (Matlab-Mathworks, Version 4.2c1; MathWorks, Inc., Natick, MA, USA, which allowed digital filtering using second-order Butterworth filters with cut-off adjusted for high- and low-pass frequencies of 1 and 12 cpm, respectively. Spectral analysis was performed using the Fast Fourier Transform, with a 256-s window applied to overlapping stretches of the signal $(12,18)$. The following variables were obtained for both fasting and postprandial recording periods: a) dominant frequency (DF), defined as the frequency at which the highest power spectrum was observed; b) DF in the various frequency ranges, the percentages of time during which gastric myoelectrical activity was recorded in the normal (2-4 cpm), bradygastria (1-1.9 cpm) or tachygastria (4$9 \mathrm{cpm}$ ) ranges; c) DF instability coefficient, the ratio between the standard deviation and the mean value for the frequencies with the highest power in the various spectrum lines. Additionally, the power ratio, defined as the ratio between the values for the highest power spectrum observed before and after the test meal was calculated for every EGG study.

An EGG was considered to be abnormal when the DF was out of the normal range (2$4 \mathrm{cpm}$ ) for more than $35 \%$ of the recording time (3). This range encompassed all healthy 
volunteers previously studied using the same test meal and similar equipment (3).

\section{Statistical analysis}

Data are reported as medians and range. All comparisons between groups and subgroups were performed using two-tailed nonparametric tests. The Mann-Whitney test was used to assess the differences regarding EGG variables between control and functional dyspepsia groups, as well as those between subgroups of patients with and without symptoms. Comparisons within-groups were made using the Wilcoxon test for paired data. The proportions of patients and controls reporting postprandial symptoms were compared using Fisher's exact probability test. Differences were regarded as significant for $\mathrm{P}$ values of less than 0.05 .

\section{Results}

\section{Postprandial symptoms}

None of the subjects presented any symptom before test meal ingestion. After the meal, none of the controls presented any

\begin{tabular}{|c|c|c|c|c|}
\hline \multirow[t]{2}{*}{ ECG variables } & \multicolumn{2}{|c|}{ Low volume } & \multicolumn{2}{|c|}{ High volume } \\
\hline & Control & FD & Control & $\mathrm{FD}$ \\
\hline $\mathrm{DF}$ (cpm) & $2.9(2.1-3.1)$ & $3.0(2.1-3.5)$ & $3.0(2.1-3.5)$ & $2.9(2.1-3.1)$ \\
\hline $\begin{array}{l}\text { DF in the normal } \\
\text { range }(\%)\end{array}$ & $94(57-100)$ & $92(58-100)$ & $87(46-100)$ & $84(76-100)$ \\
\hline Bradygastria (\%) & $4(0-29)$ & $5(0-29)$ & $7(0-23)$ & $7(0-23)$ \\
\hline Tachygastria (\%) & $7(0-42)$ & $2(0-26)$ & $4(0-46)$ & $0(0-11)$ \\
\hline DFIC (\%) & 27 (13-44) & $20(5-46)$ & $21(14-43)$ & $24(12-52)$ \\
\hline PR & $2.64(0.2-5.3)$ & $2.1(0.9-97)$ & $1.2(0.2-6.1)$ & $1.6(0.5-16.6)$ \\
\hline
\end{tabular}

Data are reported as median and (range). There were no significant differences between the two groups for any of the EGG variables. $\mathrm{cpm}=$ cycles per minute; $\mathrm{DF}=$ dominant frequency; DFIC = dominant frequency instability coefficient; $P R=$ power ratio. symptoms. In contrast, in the group with functional dyspepsia, symptoms of upper abdominal discomfort and bloating were reported by 10 patients $(71.4 \%$; $\mathrm{P}<0.002$ vs controls) after the ingestion of the low volume meal, and by 7 patients $(50.0 \%$; $\mathrm{P}<$ 0.005 vs controls) after the high volume meal. However, the difference between the proportions of patients presenting symptoms after the low and the high volume meal was not statistically significant $(P=0.44)$. In all cases, symptoms arose immediately after meal ingestion and persisted for at least half of the recording period.

\section{Electrogastrography}

Five of the 14 patients with functional dyspepsia presented abnormal fasting EGG recordings in at least one study. Nevertheless, only one patient showed an abnormal EGG (DF in the 2-4 cpm range: 58\%), with predominance of tachygastria $(26 \%$ of the DF), after the low volume, but not after the high volume test meal.

Data for the postprandial EGG variables of patients and controls are shown in Table 1. There were no significant differences between EGG data for the low and the high meal volume within any group. There were also no significant differences between patients and controls concerning the various postprandial variables for either the low or the high volume test meal.

\section{Relationships between symptoms and EGG findings}

The only functional dyspepsia patient with an abnormal EGG after the low volume test meal reported symptoms of upper abdominal discomfort and bloating in the two studies, even when presenting an entirely normal EGG after the high volume test meal. After the low volume meal, only 1 of the 10 patients with symptoms presented an abnormal EGG, and none of the 7 patients with symp- 
toms after the high meal volume had EGG abnormalities.

Data for postprandial EGG variables in the subgroups of patients with and without symptoms are shown in Table 2 . There were no significant differences between the subgroups of functional dyspepsia patients with and without symptoms after meal ingestion concerning any postprandial EGG variable.

\section{Discussion}

The present study shows that the postprandial symptoms of upper abdominal discomfort and bloating elicited by the ingestion of a relatively low calorie test meal with increasing volumes of water in patients with dysmotility-like functional dyspepsia are not associated with abnormalities in gastric myoelectrical activity revealed by cutaneous EGG.

We have reported that controlled distension of the stomach with a plastic bag positioned in the gastric fundus produced instability of gastric myoelectrical rhythm at high distension volumes (480-600 ml), which were associated with symptoms of upper abdominal discomfort and nausea (18). We therefore aimed to determine whether in more physiological settings, with subjects drinking a test meal instead of having a barostat bag inside their stomach, symptoms and gastric dysrhythmias would be produced in functional dyspepsia patients. Since the ingested meal would distribute more fully to the gastric antrum $(8,9)$, we suggested that overdistension of the gastric antrum in functional dyspepsia patients would induce gastric dysrhythmias. However, we were not able to confirm it in the present study.

It could be argued that ingestion of different volumes of water would result in unpredictable distension of the different anatomical portions of the stomach. Nevertheless, an ultrasound study (20) has shown that ingestion of stepwise increasing amounts of water produces linear increases in both proxi- mal and distal stomach dimensions. In patients with functional dyspepsia, the distal stomach size was significantly greater than in control subjects with ingested volumes equal or greater than $500 \mathrm{ml}(20)$.

Although a substantial proportion of patients (5 of 14) had EGG abnormalities in the fasting state, we did not find any consistent postprandial EGG abnormality in dysmotility-like functional dyspepsia. This finding disagrees with those from a number of other studies (3-5,15-17). On the other hand, our data agree with those reported by Jebbink et al. (21), who did not find any difference between functional dyspepsia patients and healthy volunteers concerning the incidence of gastric dysrhythmias. It is possible that such discrepancies may be related to differences in either patient selection or the definition of functional dyspepsia, or both, since there is no biological marker for the condition. The patients included in the present study fulfilled strict contemporary criteria (Rome II) for dysmotility-like functional dyspepsia (2), whereas other studies showing high proportions of EGG abnormalities in functional dyspepsia (3-5,15-17) might

Table 2. Postprandial electrogastrography (EGG) variables in patients with dysmotilitylike functional dyspepsia (FD), with and without symptoms, after a standard test meal (150 $\mathrm{ml}$ of yoghurt), followed by the ingestion of either a low $(150 \mathrm{ml}$ ) or high $(300 \mathrm{ml})$ volume of water.

\begin{tabular}{lcc}
\hline & Low volume & High volume \\
\hline FD with symptoms & $\mathrm{N}=10$ & $\mathrm{~N}=7$ \\
DF (cpm) & $2.8(2.1-3.1)$ & $3.0(2.1-3.5)$ \\
DF in the normal range (\%) & $92(57-100)$ & $85(76-100)$ \\
DFIC (\%) & $20(10-44)$ & $23(14-43)$ \\
PR & $1.8(1.1-6.9)$ & $1.7(0.2-16.6)$ \\
FD without symptoms & $\mathrm{N}=4$ & $\mathrm{~N}=7$ \\
DF (cpm) & $3.0(2.1-3.5)$ & $2.9(2.1-3.1)$ \\
DF in the normal range (\%) & $81(65-100)$ & $88(75-100)$ \\
DFIC (\%) & $22(5-46)$ & $19(12-52)$ \\
PR & $2.1(0.9-9.7)$ & $2.3(0.2-8.3)$ \\
\hline
\end{tabular}

Data are reported as median and (range). There were no significant differences between the two FD subgroups for any of the EGG variables. cpm = cycles per minute; $\mathrm{DF}=$ dominant frequency; $\mathrm{DFIC}=$ dominant frequency instability coefficient; $\mathrm{N}=$ number of patients; $P R=$ power ratio. 
also have included patients with more severe involvement of gastric motility, such as that found in idiopathic gastroparesis (13).

Differences between studies in terms of technical aspects, such as test meal composition and volume and recording time, might also contribute to the differences in results. Nevertheless, low volume, low calorie test meals (3), as well as small volumes of water (22) have been shown to induce EGG abnormalities in patients with functional dyspepsia. Furthermore, even with short length (30 min) postprandial recordings an association between nausea and tachygastria was demonstrated (23).

Although in the present study postprandial symptoms of upper abdominal discomfort and bloating were recorded in up to $70 \%$ (10/14) of patients with functional dyspepsia, no patient complained of nausea, a symptom that has been consistently associated with gastric dysrhythmias in a number of experimental conditions, both in healthy volunteers (24) and in patients (3-5,13-16). It is therefore uncertain whether the utilization of a test meal more likely to induce nausea might have produced different results and yield a stronger association between gastric dysrhythmias and symptoms.

It is also important to consider the fact that the signal captured by surface electrodes in EGG actually represents the summation of several electrical vectors corresponding to the propagation throughout the stomach of waves arising from the gastric pacemaker (12). It is therefore plausible that electrical vectors corresponding to occasional disturbances originating in one region may indeed be annulled by another similar vector generated in an opposite region. This may theoretically be responsible for the relatively low accuracy of the EGG in detecting gastric motor abnormalities (25), and also for the conflicting results $(3-5,15-17)$ obtained for this heterogeneous clinical entity named func- tional dyspepsia $(1,2)$.

The origin of postprandial symptoms in dysmotility-like functional dyspepsia is unclear. Although a number of physiological abnormalities have been well demonstrated in this situation, their relationship to symptoms has not been definitely established (26). Nevertheless, various mechanisms may explain why symptoms following a meal may arise independently of either the appearance of gastric dysrhythmias or their potential consequences, such as antral hypomotility and delayed gastric emptying. Upper abdominal discomfort, bloating, and nausea may be caused by impaired fundal relaxation $(10,11)$, leading to increased intragastric pressure (10) and antral overdistention produced by displacement of food from the proximal to the distal stomach $(8,9)$ Furthermore, increased sensitivity to gastric distention due to visceral hyperalgesia (27) may also be involved in symptom production. The elucidation of the roles of each of these physiological abnormalities in the pathogenesis of functional dyspepsia demands further studies, which will probably require multiple and sophisticated methods to approach several mechanisms.

The observations made in the present study do not support the view that disturbances of gastric myoelectrical activity play a role in the origin of postprandial symptoms of upper abdominal discomfort and bloating, which were found in substantial proportions of patients with dysmotility-like functional dyspepsia, even after the ingestion of low volume, low calorie meals.

\section{Acknowledgments}

The authors are indebted to Miss Ana Maria Borges for excellent technical assistance and to Professor Ricardo B. Oliveira, MD, who carefully revised the manuscript. 


\section{References}

1. Heading RC (1991). Definitions of dyspepsia. Scandinavian Journal of Gastroenterology, 26 (Suppl 182): 1-6.

2. Talley NJ, Stanghellini V, Heading RC \& Koch KL (1999). Functional gastroduodenal disorders. Gut, 45 (Suppl II): II-37-II-42.

3. Rezende Filho J (1995). Estudo da atividade mioelétrica gástrica por eletrogastrografia cutânea - Eletrogastrograma. Arquivos de Gastroenterologia, 32: 54-65.

4. Pfaffenbach B, Adamek RJ, Bartholomaus C \& Wegener M (1997). Gastric dysrhythmias and delayed gastric emptying in patients with functional dyspepsia. Digestive Diseases and Sciences, 42: 20942099.

5. Lin Z, Eaker EY, Sarosiek I \& McCallum RW (1999). Gastric myoelectrical activity and gastric emptying in patients with functional dyspepsia. American Journal of Gastroenterology, 94: 2384-2389.

6. Stanghellini V, Ghidini C, Ricci MM, Paparo GF, Corinaldesi R \& Barbara $L$ (1992). Fasting and postprandial gastrointestinal motility in ulcer and nonulcer dyspepsia. Gut, 33: 184-190.

7. Corinaldesi R, Stanghellini V, Raiti C, Rea E \& Salgemini R (1987). Effect of chronic administration of cisapride on gastric emptying of a solid meal and on dyspeptic symptoms in patients with idiopathic gastroparesis. Gut, 28: 300-305.

8. Troncon LEA, Bennett RJM, Ahluwalia NK \& Thompson DG (1994). Abnormal intragastric distribution of food during gastric emptying in functional dyspepsia patients. Gut, 35: 327-332.

9. Hausken T \& Berstad A (1992). Wide gastric antrum in patients with non-ulcer dyspepsia. Scandinavian Journal of Gastroenterology, 27: 427-432.

10. Troncon LEA, Thompson DG, Ahluwalia NK, Barlow J \& Heggie LJ (1995). Relations between upper abdominal symptoms and gastric distension abnormalities in dysmotility like functional dyspepsia and after vagotomy. Gut, 37: 17-22.

11. Tack J, Piessevaux H, Coulie B, Caenepeel P \& Janssens J (1998). Role of impaired gastric accommodation to a meal in functional dyspepsia. Gastroenterology, 115: 1346-1352.

12. Smout AJPM, Van Der Schee EJ \& Grashuis JL (1980). What is measured in electrogastrography? Digestive Diseases and Sciences, 25: 179-187.

13. Telander RL, Morgan KG, Kreulen DL, Scmalj PF, Kelly KA, Szurzewsky JH (1978). Human gastric atony with tachygastria and gastric retention. Gastroenterology, 75: 497-501.

14. Koch KL, Stern RM, Stewart WR, Vasey MW \& Sullivan ML (1989). Gastric emptying and gastric myoelectrical activity in patients with diabetic gastroparesis: Effect of long-term domperidone treatment. American Journal of Gastroenterology, 84: 1069-1075.

15. Geldof H, van der Schee EJ, van Blankstein M \& Grashis JL (1986). Electrogastrographic study of gastric myoelectrical activity in pa- tients with unexplained nausea and vomiting. Gut, 27: 799-808.

16. Chen J, Lin Z, Pan J \& McCallum RW (1996). Abnormal gastric myoelectrical activity and delayed gastric emptying in patients with symptoms suggestive of gastroparesis. Digestive Diseases and Sciences 41: 1538-1545.

17. Parkman H, Miller M, Trate D, Knight LC, Urbain JL, Maurer AH \& Fisher RS (1997). Electrogastrography and gastric emptying scintigraphy are complementary for assessment of dyspepsia. Journal of Clinical Gastroenterology, 24: 214-219.

18. Taylor EJ \& Troncon LEA (1993). The use of Fourier transform and spectral analysis in the detection of distension-induced gastric arrhythmias in dyspeptic patients. Physiological Measurements, 14: 137-144.

19. Parkman HP, Harris AD, Miller MA \& Fisher RS (1996). Influence of age, gender, and menstrual cycle on the normal electrogastrogram. American Journal of Gastroenterology, 91: 127-133.

20. Marzio L, Falcucci M, Grossi L, Ciccaglione FA, Malatesta MG, Castellano A \& Ballone E (1998). Proximal and distal gastric distension in normal subjects and H. pylori-positive and -negative dyspeptic patients and correlation with symptoms. Digestive Diseases and Sciences: 43: 2757-2763.

21. Jebbink HJA, Van Berg-Henegouwen GP, Bruijs PPM, Akkermans L \& Smout AJPM (1995). Gastric myoelectrical activity and gastrointestinal motility in patients with functional dyspepsia. European Journal of Clinical Investigation, 25: 429-437.

22. Koch KL, Hong SP \& Xu L (2000). Reproducibility of gastric electrical activity and the water load test in patients with dysmotility-like dyspepsia symptoms and control subjects. Journal of Clinical Gastroenterology, 31: 125-129.

23. Koch KL, Stern RM, Vasey M, Botti JJ, Creasy GW \& Dwyer A (1990). Gastric dysrhythmias and nausea of pregnancy. Digestive Diseases and Sciences, 35: 961-968.

24. Stern RM, Koch KL, Stewart WR \& Lindblad IM (1987). Spectral analysis of tachygastria recorded during motion sickness. Gastroenterology, 92: 92-97.

25. Bortolotti M (1998). Electrogastrography: a seductive promise, only partially kept. American Journal of Gastroenterology, 93: 17911794.

26. Malagelada JR (2001). Review article: the continuing dilemma of dyspepsia. Alimentary Pharmacology and Therapeutics, 15 (Suppl 1): 6-9.

27. Lémman M Dederding JP, Flourié B, Franchisseur C, Ramband JC \& Jian R (1991). Abnormal perception of visceral pain in response to gastric distension in chronic idiopathic dyspepsia. Digestive Diseases and Sciences, 36: 1249-1254. 